\title{
Наследники Абу Бакра: об идеологии и концепции истории в Аль-Каиде и Исламском государстве
}

\section{Якоб Сковгаард-Петерсен}

Университет Копенгагена, $h t t p: / / c c r s . k u . d k$

\begin{abstract}
Резюме: В этой работе рассматриваются ссылки Аль-Каиды и Исламского государства на раннюю историю мусульманства и отмечается наличие существенных различий. Тогда как Аль-Каида традиционно ссылается на битвы ранних мусульман во времена пророка Мухаммеда, Исламское государство, в основном, ссылается на наследника пророка, халифа Абу Бакра. Поэтому Аль-Каида, в соответствии с идеей Сайида Кутб о "Коранической программе», говорит о мифическом прошлом, как будто оно повторяется по-новому сегодня. Исламское государство, в свою очередь, придерживается более прагматической линии, утверждая, что события сегодня, как и во времена первых халифов, являются просто результатом человеческих решений в пост-пророческом и пост-кораническом веке.
\end{abstract}

Ключевые слова: Аль-Каида, Исламское государство, Абу Бакр, халифат, идеология.

\section{Введение}

Перестал ли Халифат существовать в 1924 году, или он распался после Монгольского нашествия на Багдад в 1258 году? Усама Бен Ладен и АльКаида (АК) верили в первое утверждение, тогда как Абу Бакр аль-Багдади и ИГ, похоже, верным считают второе.

В этой работе будут проанализированы различия между использованием исторических ссылок этими двумя движениями и будут рассмотрены последствия этих отличий. Несмотря на значительные ресурсы, выделяемые на изучение Исламского государств (ИГ), эта проблема, в частности, все еще не была объектом систематического рассмотрения исследовате- 
лями, и данное исследование является всего лишь первой попыткой. Предметом исследования являются те немногие основные идеологии, которые используют ранние исламские войны, для оправдания сегодняшних войн, хотя каждая делает это по-своему. В работе исследуется вопрос, как эти идеологии вошли в конфронтацию между собой в последние полтора года.

\section{Этапы джихадизма}

Известно, что концепция джихада в мусульманской истории использовалась в связи с несколькими религиозными починами, например, в связи с аскетизмом, но в исламском праве и политическом мышлении джихад принял значение непосредственно войны против не-мусульман. Сегодня в арабском языке это понятие может использоваться в полностью секуляристком контексте, например, в отношении классовой борьбы или в связи с национально-освободительными усилиями. Однако доминирующим пониманием этой концепции является значение «война во имя Бога» (фи сабил Аллах), и это понимание стало еще более ярко выраженным в последние 50 лет джихадизма.

В Дании политики и комментаторы в целом используют не термин джихадизм, а исламизм, и кажется, есть общий консенсус, что феномен исламизма появился в 1928 году, когда в Египте Хассан аль-Банна организовал движение «Братья-мусульмане». Это соответствует и фактам. Однако исламизм является многогранной концепцией. Как предполагает само слово, исламизм рассматривает ислам как политическую идеологию и модель для организации государства и общества. Однако, есть существенные разногласия по вопросу о том, как должны быть организованы государство и общество. Некоторые исламисты отвергают парламентскую демократию, тогда как другие заявляют, что демократия упоминается в Коране; некоторые исламисты отвергают конституцию, тогда как другие считают, что сама концепция «конституции» была введена Мухаммедом в Медине. Дискуссия о датской внешней политике страдает от участия людей, которые используют понятие исламизм, не понимая его точного значения; все, что они знают, это то, что они должны держаться подальше от него. Однако, если не делается отличие между разными формами исламизма, невозможно понять, что происходит в мусульманском мире или даже в среде мусульман в Дании. K примеру, в Сирии некоторые исламистские группы воюют на стороне режима, другие на стороне повстанцев или ИГ.

Члены Исламского государства являются исламистами в смысле, что они придерживаются идеологии, предполагающей создание исламских государств и исламских обществ. Их корни восходят к «Братьям-мусульманам» и другим исламистским движениям. Но сегодня они очень критически настроены к более широким исламистским движениям. Их стратегиче- 
ская и идеологическая позиция совершенно другая, и поэтому здесь я буду использовать термин джихадизм.

Согласно джихадистской идеологии, джихад является обязанностью каждого отдельного мусульманина, в том числе и джихад против тех, кто утверждают, что они мусульмане, но не разделяют эту идеологию; против людей, которых надо считать лицемерами и вероотступниками в смысле Корана. Так как настоящих мусульман мало и они участвуют в неравной битве против мировых тиранов (maвагхит), скорее всего, они погибнут в боях. Однако этого как раз и ожидает Бог от них, и его наградой им будет Рай, а так же гарантия, что пока они на земле, немногих настоящих воинов в конце ожидает победа (am-Tauфa аль-Мансура).

Идеология небольшой авангардной группы настоящих верующих, которые понимают требование Господа вести войну, впервые в арабском мире была сформулирована Сайидом Кутб (1906-66) в 1950-х - десятилетии, когда мусульманские государства наконец получили независимость. Идеология этих новых государств была основана на национализме, и исламистские движения, которые рассматривали ислам как современную государственную идеологию, подверглись маргинализации и иногда безжалостно подавлялись. В 1970-х в разных местах были созданы основанные на идеи Кутба движения, которые, как и революционные социалисты и националисты, считали, что насилие является законным средством для достижения политических целей. В 1980-х эти джихадисты шли в Афганистан, в который вторгся Советский Союз, и аль-Муджахидийн (арабское слово, означающее "те, кто делает джихад») финансировались, готовились и вооружались пакистанскими, саудовскими и американскими разведками.

Став таким образом профессиональной, в 1990-х часть джихадистского движения решила начать глобальную джихадистскую борьбу против гегемонии США, которая достигла кульминации в атаках в 2001 году. В борьбе против АК, в которой с тех пор участвуют США, многие из лидеров движения были уничтожены или взяты в плен, но движению на практике не было нанесено поражение. Новые идеологические лидеры, например Абу Мусаб аль-Сури, следовали стратегии, согласно которой движение не концентрируется на некой (уязвимой) территории, а организовано в виде свободных, автономных сетей, и не на последнем месте в Европе. ${ }^{1}$ Известный исследователь джихадизма, Жиль Кепель, называет это третьим этапом джихадизма, который следует за национальной и глобальной фазой. ${ }^{2}$ В исламском мире другой идеолог, Абу Бакр Наджи, пропагандировал стратегию использования крайнего насилия для дестабилизации и осуществления контроля над территориями с тем, чтобы сделать их неуправляемыми так, чтобы граждане постепенно приняли жесткий исламский режим пра-

1 Brynjar Lia, Architect of Global Jihad. The Life of al-Qaida Strategist Abu Musab alSuri (London: Hurst and Oxford University Press, 2007), p. 7.

2 Gilles Kepel, Beyond Terror and Martyrdom (Cambridge, MA: Harvard University Press, 2010), p. 110. 
вопорядка. Идея для этого была порождена развитием событий в Ираке, где относительно успешная инвазия США в 2003 году столкнулась с серьезнейшими проблемами, когда офицеры разведывательных служб свергнутого диктатора Саддама Хусейна объединили свои силы с джихадистами из $\mathrm{AK}^{3}$

\section{Абу Мухаммад аль-Макдиси и Абу Катада}

Изложенную выше историю рассказывали много раз. Мы пойдем дальше и рассмотрим более пристально двух других известных джихадистских идеологов, которые поддерживают АК, и то, что они называют глобальным джихадистким движением. Мы увидим, что эти два идеолога спорят с ИГ. Оба они палестинцы из Иордании, оба были рождены приблизительно в 1960 году, как и я, но они отрастили гораздо более длинные бороды.

Возможно, более важным из них двух является Абу Мухаммад альМакдиси (рожденный в 1959 году). Аль-Макдиси вырос в Кувейте и учился в нескольких университетах, но в основном он самообразовывался. С самого начала его целью являлось объединение повстанческой идеологии политического исламизма с консервативной теологией салафизма, и он нашел связь между ними в классическом ваххабизме. В своей первой книге, Миллат Ибрагим (1984), он модернизировал классический ваххабизм, применяя традиционное (кораническое) понятие бара' (воздерживаться от и отвергать политеизм так же, как и Авраам) к сегодняшним мусульманским президентам и королям и их политическим системам. В то же время он подчеркивает, что осуждение только в своем сердце является слишком слабым; ненависть и джихад более достойны похвалы. Таким образом, он подготавливает почву для конфронтации с политической элитой, но не обвиняя мусульман в ереси, если они не хотят заходить так далеко. ${ }^{4}$ После того, как палестинцы были выгнаны из Кувейта в 1991 году, аль-Макдиси прибыл в Иорданию, где он и один студент, Абу Мусаб альЗаркави, создали военизированную группу. Вскоре после этого он был заключен в тюрьму и был в заключении с 1994 по 1999 год. С тех пор он живет в Иордании.

Другим идеологом АК является друг аль-Макдиси, Абу Катада аль-Филстини (рожденный в 1960). Абу Катада тоже является самоучкой, и в конце 1980-х он обретался в Пакистане. Однако, прежде всего он известен как проповедник в Лондоне в 1990-х, который в результате длительного судебного разбирательства был депортирован из Соединенного Королевства в Иорданию в 2013 году. Тогда как аль-Макдиси ведет себя спокойно, Абу

3 Lars Erslev Andersen, "The Mole and the Mallet: Islamic State and al-Qaeda in the 'Thirty Years' War' in the Middle East," Connections: The Quarterly Journal 16, no. 1 (Winter 2017): 7-24, https://doi.org/10.11610/Connections.16.1.01.

4 Joas Wagemakers, A Quietist Jihadi. The Ideology and Influence of Abu Muhammad al-Maqdisi (Cambridge: Cambridge University Press, 2012), pp. 170-173. 
Катада агрессивен и любит делать провокационные заявления, очевидно для того, чтобы повысить осведомленность о джихадизме в более широких кругах и завербовать новых боевиков.

После того как США и коалиция разных стран вошли в Ирак в 2003 году, аль-Макдиси поддержал борьбу против западных сил, как и все другие джихадисты. Однако, в это самое время аль-Макдиси опубликовал несколько писаний, в которых критикует аль-Заркави за использование крайнего насилия и самоубийственных терактов, и за то, что он обвиняет в ереси не только мусульман-шиитов, но и суннитов в Ираке. Аль-Заркави ответил заявлением против аль-Макдиси, в котором он обвинил аль-Макдиси в том, что он стал более критичным к нему, чтобы выйти из тюрьмы. ${ }^{5}$ Отголоски перестрелки в 2005 году между этими двумя идеологами прозвучали через десять лет после этого, когда аль-Макдиси из базы в Иордании раскритиковал ИГ, которое заявило, что аль-Заркави является их идеологическим основателем.

\section{Кто тогда является идеологом ИГ?}

У ИГ есть свои идеологи, и как и аль-Макдиси и Абу Катада, у них не было продолжительной карьеры в исламских исследовательских институциях. Наоборот, они хотели оторваться от установленного ислама.

Наиболее известным официальным представителем ИГ был Мухаммад аль-Аднани, который был убит при воздушном ударе США летом 2016 года. Он был сирийцем из северного города Бинниш, где был рожден в 1977 году и где ему дали имя Таха Субхи Фалаха. Хотя они и были в Пакистане, аль-Макдиси и Абу Катада являются только идеологами, тогда как аль-Аднани был настоящим воином. Он принимал участие в восстании против инвазии войск США в Ирак в 2003 году, где он и встретился с Абу Мусааб аль-Заркави. Аль-Заркави был лидером АК в Ираке, но трения между ним и лидерами в Пакистане заставили его идти своим собственным путем, пока он не был убит в 2006 году. Аль-Аднани провел несколько лет в тюрьме и стал частью внутреннего круга ИГ в Ираке. Он был очевидным кандидатом на роль руководителя, когда движение направилось в Сирию в 2012 году, и именно он объявил о создании халифата в начале священного месяца Рамадан в 2014 году.

Другой идеолог ИГ - это молодой Турки Бинали, который рожден в Бахрейне в 1984 году. После коротких периодов обучения в Бахрейне, Бейруте и Дубае он привлек внимание к себе как к верному последователю Мухаммада ибн Абд аль-Ваххаба, пуританского мыслителя 18-го века, который в некотором смысле является национальным идеологом Саудовской Аравии. Ибн Абд аль-Ваххаб сопротивлялся любым религиозным инновациям и призывал к вооруженной реакции против всякого, который не следовал его пуританской интерпретации ислама. Сегодня Саудовская

5 Wagemakers, A Quietist Jihadi, p. 48. 
Аравия не является настолько ваххабитской, насколько она была раньше, и Бинали и ИГ обвиняют монархию за такое развитие событий. Они публикуют писания Мухаммада ибн аль-Ваххаб в Интернете, указывая на противоречия с современной Саудовской Аравией, и они стоят за терактами со взрывными устройствами против шиитского меньшинства в стране, которое маргинализовано монархией, но которое не уничтожено полностью, как хотел бы ибн Абд аль-Ваххаб. В апреле 2014 года Турки Бинали опубликовал заявление, дающее юридическое основание для учреждения халифата, хотя не имелись в наличности все предпосылки для этого. Оправдание состояло в том, чтобы ускорить процесс на основании аята Корана 24:55, в котором сказано, что Бог обещал наградить всех настоящих верующих халифатом. Аль-Аднани использовал этот аргумент в своем объявлении о создании Халифата, «Обещание Бога».

\section{Как стать халифом}

Восстание 2011 года в Сирии быстро привело к тому, что джихадистское движение в Ираке двинулось в Сирию; сначала это сделали Абу Мухаммад аль-Джавлани и группировка Фронт Джебхат ан-Нусра, а позже Абу Бакр аль-Багдади и ИГ в Ираке и Леванте (ИГИЛ или ИГИС). Международный лидер АК, Айман аль-Завахири, поддержал Фронт ан-Нусра, и зимой 201415 оба эти движения уже воевали друг против друга. Фронт ан-Нусра и его союзники победили.

Однако, не далее, как следующим летом, внезапной атакой ИГИЛ успело захватить большой иракский город Мосул, и именно в этом городе аль-Аднани на символической дате первого дня Рамадана объявил альБагдади первым халифом. ИГИС сменило свое название на ИГ и с тех пор движение «остается и расширяется» (девиз движения) в западной части Ирака и восточной части Сирии, хотя при всевозрастающих людских потерях. В пятницу после прокламации Халиф произнес свою инаугурационную проповедь в Большой мечети аль-Нури, цитируя известные слова первого халифа Абу Бакр из его инаугурационной проповеди в 632 году: «Если я делаю правильно, помоги мне; если я ошибаюсь, поправь меня».

Через несколько дней Абу Катада послал заявление в Халифат, в котором он осуждал нового Халифа за то, что он является незаконным (батил). Согласно исламскому праву, Халиф назначается советом компетентных представителей мусульман (ахл аш-шура - джихадисткие лидеры со всего света). В интервью международной газете аль-Шарк аль-Асват, данном из его камеры в иорданской тюрьме, Абу Катада назвал это заявление стратегическим ходом, направленным не на всех мусульман, а являющимся попыткой опередить более широкий, ориентированный на АК джихадизм. Кроме того, он заявил, что методы аль-Багдади «являются сочетанием не- 
успешных элементов из аль-равафид и аль-хаваридж». ${ }^{6}$ Это серьезное обвинение в джихадистской вселенной; аль-равафид - это обидное словосочетание для обозначения мусульман-шиитов, и аль-хаваридж - это религиозное течение, которое стало причиной для споров между мусульманами вскоре после смерти Пророка из-за жесткой и отличающейся нетерпимостью позиции по вопросу, кто может быть мусульманином и кто может быть лидером, и потому что на него возлагали ответственность за смерть четвертого Халифа, Али.

По последнему пункту этой критики весной уже высказывался Турки Бинали. В десятистраничном «Заявлении в ответ Абу Катада» Бинали рассуждал о том, как человек масштаба Абу Катада, который опубликовал книги такой величины и важности, может всадить нож в спину моджахедам. Это возможно только при полном отсутствии представления об их ситуации и из-за неблагоприятного развития событий в тюрьме. Бинали предположил, что Абу Катада просто использовали в качестве инструмента иорданские службы разведки. Он заключил, что книгам Абу Катада все еще можно верить, но уже нельзя верить любым заявлениям, которые он делает из тюрьмы.

После объявления Халифата, Мухаммад аль-Аднани, другой главный идеолог ИГ, выпустил в свет еще более жесткий ответ критикам джихадизма: люди могут слушать мусульманских ученых по всему свету, но они так же видят, кто побеждает. Мы побеждаем. Поэтому Бог поддерживает нас. Мухаммад аль-Макдиси тоже много спорил с лидерами ИГ. Как ментор аль-Заркави, которого ИГ считает своим первым лидером, он верил, что сможет оказать влияние на ИГ, когда Муадх аль-Касасиба, иорданский пилот, был сбит, и ИГ объявило, что они его казнят. Но аль-Макдиси не только не смог спасти аль-Касасиба; он узнал, что ИГ уже казнило пилота, пока они вели переговоры с аль-Макдиси. ${ }^{7}$

Короче, большого взаимного уважения не было. Кульминация ухудшения отношений наступила, когда аль-Макдиси и Абу Катада вместе подписали фетву, которая позволяла истинным моджахедам воевать против ИГ в целях самозащиты. Они называли ИГ «багдадистами», т.е. приверженцами секты, руководимой аль-Багдади. ${ }^{8}$ В это время ИГ и Джебхат ан-Нусра были уже в прямом конфликте в Алеппо.

Абу Катада и аль-Макдиси не единственные идеологи, связанные с АК, которые входили в конфронтацию с аль-Аднани, но они среди самых из-

6 Muhammad Al-Da'ma, “al-da'iyya al-urduniyya al-mutashaddad Abu Qatada yantaqad I'lan al-khilafa al-islamiyya," Al-Sharq al-Awsat 16, nо. 7 (2014), доступно Ha http://aawsat.com/home/article/139131.

7 Joas Waagemakers, Al-Maqdisi in the Middle. 2015; доступно на http://www.jihadica.com/maqdisi-in-the-middle-an-inside-account-of-the-secretnegotiations-to-free-a-jordanian-pilot/.

8 Abu Qatada al-Filastini, Muhammad al-Maqdisi et al.: Fatwa, June 3, 2015, доступно на http://www.jihadica.com/wp-content/uploads/2016/05/fatwa-June-3-2015.pdf. 
вестных, и столкновения между ними происходили периодически в течение некоторого времени, в последний раз в мае 2016 года, когда ИГ опубликовало длинный документ, «Забвение икон». В этом документе говорилось, что джихадистских идеологов, которые выражали сочувствие к «Братьям-мусульманам», не следует считать частью движения настоящих верующих, потому что «Братья» восприняли парламентаризм, сотрудничество с неверными и т.д. ${ }^{9}$ Документ был направлен против идеолога АК, Абу Мусааб аль-Сури, но его можно было бы отнести и к Абу Катада, который после революций 2011 года был обнадежен общественной поддержкой исламистских движений, хотя считал, что их следует немедленно подвергнуть критике. ${ }^{10}$ Всего два дня после публикации «Забвение икон», альМакдиси сделал заявление, в котором говорилось, что это забвение, распространившееся и на мучеников религии, показывает, что ИГ превратилось в экстремистскую секту (гхулв), которая распрощалась со своими наиболее знающими идеологами. ${ }^{11}$

\section{История Халифата}

Разные интерпретации политических авторитетов находят отражение и в разных датировках падения Халифата. Усама Бен Ладен, похоже, следовал тому же самому курсу, который нам известен от Хизб-ут-Тахрир в Дании. Придерживающиеся этой точки зрения считают, что западные силы, в том числе и ранние ционисты, решили подорвать Оттоманский халифат, сначала в 1876 году введя конституцию, и снова в 1908 году организовав революцию младотурков, когда националисты свергли богобоязненного Абд аль-Хамида II и поставили другого халифа, которого они могли контролировать. Третий случай имел место в 1924 году, когда новоучрежденный турецкий парламент решил упразднить должность халифа.

Для ИГ Оттоманский халифат не был настоящим халифатом потому, что Оттоманы не происходили из племени Пророка Кураиш. По их мнению, Халифат пал 750 лет до этого, во время монгольского нашествия на Багдад и убийства Мустасима, последнего халифа из рода Аббасидов, которого завернули в ковер и утопили в реке Тигр. Члены династии Аббасидов, которая правила с 750 по 1258 год, были настоящими потомками курайшитов, но со временем династия ослабла. Поэтому для ИГ первичным источником вдохновения является основание этой династии приблизительно в 750 году. Неся черные флаги, повстанцы пришли из Хорасана (области, ко-

9 Abu Maysara al-Shami, Tamas al-rumuz (2016), доступно на https://azelin.files. wordpress.com/2016/05/abucc84-maysarah-al-shacc84micc84-22obliteration-ofthe-icons-abucc84-muscca3ab-al-succ84ricc8422.pdf.

10 Abu Qatada al-Filastini, al-Muqaraba li nazilat al-'asr. Copenhagen: al-Nur, 2012.

11 Muhammad Al-Maqdisi, al-radd 'ala Abu Maysara, 2016, доступно на http://jihadology.net/2016/05/14/new-release-from-shaykh-abu-mu\%e1\%b8\%a5 ammad-al-maqdisi-reply-to-abu-maysurah-on-seeking-to-obliterate-the-icons/. 
торая сейчас включает северо-восточную часть Ирана и южную часть Средней Азии), чтобы бороться с морально коррумпированной династией Омейядов в Дамаске. Столица Аббасидов временно размещалась в Ракке, прежде чем была перенесена в Багдад - у ИГ тоже есть такая мечта. ИГ сознательно проводит такие параллели: движение использует тот же флаг, и они дают названия территориям по наименованиям старых провинций при Аббасидах (вилаят). Кроме того, халиф принял имя аль-Багдади аль-Курайши, означающее, что он является потомком курайшитов и что он из Багдада. Его настоящее имя Аввад Ибрагим аль-Бадри, и он рожден в другом иракском городе, Самарра. Но важнее то, какое собственное имя он выбрал: Абу Бакр.

\section{Абу Бакр}

Абу Бакр был близким другом и братом по оружию Пророка. Он так же стал преемником Пророка, и слово «халиф» означает «преемник Пророка». В 632 году, в ночь, когда умер Пророк, состоялся большой совет (шура) для обсуждения будущего. Было несколько кандидатов на должность лидера, но все устроилось, когда Умар, один из братьев по оружию Пророка, сильным и ясным голосом произнес клятву на верность (байя) Абу Бакр, и другие последовали за ним. Скоро Умар сам стал Халифом, когда Абу Бакр умер в 634 году.

ИГ рассматривает два года власти Абу Бакр как путеводный свет для своей стратегии и законности потому, что этот период представляет собой время, когда государство постепенно приобретало форму, хотя многие стороны государства оставались все еще весьма неясными. Во-первых, многие арабские племена изменили клятве верности мусульманам потому, что они считали эту клятву личной клятвой Мухаммеду, который уже умер. Поэтому, большую часть времени и усилий Абу Бакра уходило на войну с этими племенами, чтобы заставить их возобновить свою клятву. Эти войны известны как войны Ридда, что означает войны против вероотступников. ИГ использует тот же термин для своих войн против арабских племен в Сирии и, в частности, в Ираке, где племена объединились с силами США в восстании против ИГ в Ираке (ИГИ), предшественника ИГ. После 2014 года племена либо терпели поражение, либо шли на сотрудничество. Некоторые просто были уничтожены, а другие вынуждены присягнуть на верность Абу Бакр на величественных церемониях и принимать участие в программах по переобучению, которые будто бы сделаны по примеру того, как Халиф Абу Бакр образовывал арабские племена. ${ }^{12}$ Девиз ИГ «остаться и расширяться» базируется на победе над вероотступничеством и на смелых наступлениях на новые территории (и на финансово значимой военной добыче).

12 Michael Weiss and Hassan Hassan, ISIS. Inside the Army of Terror (New York: Regan Arts, 2015), pp. 200-210. 
В длинной статье своего пропагандистского журнала на французском языке «Дар ал-Ислам» ИГ объясняет, насколько старательно оно следует по следам Абу Бакра и соратников Пророка.

Поэтому необходимо - сегодня более, чем когда-либо - вернуться во времена рассказов о наших благочестивых предках, чтобы проанализировать и сравнить их работу с работой ИГ. Только проведя такое сравнение, настоящие искатели могут правды убедиться, что сегодня ИГ марширует по следам соратников [...] Поскольку сейчас учрежден Халифат и все государства неверующих и вероотступников объединили свои силы, чтобы бороться с ним, наступило время обратиться к истории исламских завоеваний [...] В этой статье мы вспоминаем битвы, которые вел халиф Абу Бакр аль-Сиддик, и в частности, завоевание Ирака, что является жизненно важным вопросом, требующим сегодня всего нашего внимания. ${ }^{13}$

Основным моментом статьи является утверждение, что Абу Бакр решил атаковать намного большую и более сильную персидскую империю Сасанидов, которая охватывала территории, находящиеся в сегодняшнем Ираке, хотя в то же время он был занят войнами Ридда против вероотступнических племен. Поэтому он перенаправил свои силы на север к портовому городу Убулла и далее к аль-Хира, главному персидскому городу в Месопотамии. Оставаться и расширяться в одно и то же время было труднейшим предприятием. Но эта неравная битва была сознательной стратегией Абу Бакра потому, что он знал, что Бог не позволит, чтобы умма была уничтожена. Таким образом, Абу Бакр создал государство и верных мусульман, которые стали моджахедами, а ложные верующие, лицемеры, были уничтожены. С использованием сочетания рассказов о разных битвах, речей Абу Бакра перед его солдатами и цитат идеолога ИГ Абу Мухаммада Аднанис, в статье показано, что ИГ старательно следует стратегии Абу Бакра:

Это секрет ИГ и его сегодняшних битв. Оно никогда не полагается на свою силу, на свою подготовку или на свою численность. Оно полностью полагается на Бога, поскольку только Бог может обеспечить победу: «и нет победы, кроме как от Аллаха, всемудрого и всемогущего» ([Коран сура 3] Аль Имран, стих 126). Послание Абу Бакра аль-Сиддик его солдатам является ключом к победе. Поэтому у командиров ИГ нет иного выбора, кроме как отправить такое же послание своим солдатам. Шейх Абу Мухаммад аль-Аднани сказал: «Солдаты ИГ, вслушайтесь в эти слова. Не бойтесь за Халифат, поскольку Аллах (да возвыситься хвала ему) защитит и направит Халифат и людей, которые его создают. Но бойтесь о себе, о своих душах, покайтесь и вернитесь к своему Господу». ${ }^{14}$

13 “L'ètat islamique sur les par des compagnons," Dar al islam, May 9, 2016, p. 7.

14 Там же, стр. 11. 
Идея тут в том, чтобы заставить солдат ИГ воевать против вероотступников и тем, кто погибнет в этой борьбе, обещан вход в Рай. В статье приводятся примеры времен ранних завоеваний, когда отдельные воины и небольшие группы, благодаря презрению к смерти, побеждали гораздо более сильные вражеские контингенты. Мораль статьи совершенно такая же, как и мораль ИГ: даже сегодня войны выигрывают те, кто не страшится смерти, а любит ее.

\section{Абу Катада и войны Пророка}

Этот последний тезис - что ислам победит потому, что правоверные мусульмане имеют более высокий дух, чем остальные солдаты - хорошо известен в исламистской литературе. ${ }^{15}$ Однако они рассматривают джихад как оборонительную войну для защиты, например, мусульманской Палестины.

Представление о джихаде как о наступательной войне и индивидуальной обязанности является торговой маркой идеологического джихадизма, чьим духовным отцом в арабском мире был Сайид Кутб. В его пространных комментариях к Корану «В тени Корана», изданных в 1958 году, Кутб развивает идею, что истинный верующий должен отказаться от безбожного и варварского общества, в котором он был рожден, и от грешной жизни, которую он вел. Кутб называет это хиджрой, слово, которое также используется для обозначения исхода Пророка Мухаммеда из грешной Мекки в Ятриб, город, в котором было создано первое мусульманское сообщество. Как и Пророк, каждый мусульманин должен пройти свою хиджру, говорит Кутб, но только немногие - авангард - делают это. Из-за того, что совсем немногие осуществляют истинный ислам, мы все еще живем во «времена слабости», индивидуальной и коллективной.

АК и многие из идеологов движения были вдохновлены восприятием жизни Пророка в качестве модели борющегося правоверного и Корана в качестве программы (минхадж): они хотят видеть создание джихадистского движения в Афганистане в виде хиджры - небольшой группы верующих, и битвы, ведомые оттуда в виде модели битв, которые Пророк вел из Ятриба (который он назвал Мединой) против прежних угнетателей мусульман в языческой Мекке. Идеологи описывают разные террористические акты, в том числе и нападение на Всемирный торговый центр в 2001, как «рейды» или газва, откуда и происходит слово “раззиа» и слово, используемое мусульманскими историками для обозначения нападений Пророка на караваны из Мекки.

Абу Катада написал обзор рейдов Пророка Мухаммеда, который предназначен служить в качестве инструкции для сегодняшних моджахедов. На более, чем 732 страницах на арабском, он проходит через почти 20 боль-

15 Sami E. Baroudi, "Sheikh Yusuf Qaradawi on International Relations: The Discourse of a Leading Islamist Scholar (1926-)," Middle Eastern Studies 50, no. 1 (2014): 2-26. 
ших и маленьких рейдов, осуществленных Пророком в течение девяти лет с 624 по 632 год. Это делали и до него, основываясь на биографиях Мухаммеда, составленных мусульманскими историками. Однако, идея Абу Катада другая, поскольку он фокусирует свое внимание на стихах Корана, касающихся отдельных битв и на том, как Бог создает умму и каждого отдельного мусульманина. Войны являются этапами в программе Бога для каждого настоящего верующего, божественным формированием характера.

Поэтому, Абу Катада посвящает более одной четверти своей книги одному конкретному рейду, который закончился поражением, а именно, битве при Ухуде. Мусульмане реагировали по разному, когда они встретились с превосходящей армии из Мекки; воины были встревожены, некоторые вышли слишком рано, другие совсем не вышли. Это было тяжелое время для каждого потому, что поражение при Ухуде случилось после чудотворной победы на Бадре, которая сделала мусульман очень самоуверенными и беспечными. Абу Катада восхваляет Битву при Ухуде, потому что она привела к отделению настоящих верующих от лицемеров, и дала возможность многим воинам стать мучениками. При Ухуде Бог дал понять, что джихад и есть сама жизнь и единственный способ засвидетельствовать свою веру в Бога. ${ }^{16}$ Бог раскрыл, среди прочих вещей, стих «Аллах любит стойких» (Коран 3:146), поскольку битва является величайшим испытанием для первых мусульман. Терпение не означает терпимость, а стойкость. Это не смирение животных или личностей; это исполненное верой, терпеливое ожидание подходящей возможности. ${ }^{17}$ Поэтому, Абу Катада не рассматривает джихад как убивание, а как часть цивилизационного процесса: формирования государства и личности. Он заканчивает свой обзор констатацией, что джихад это дело народа; нечто в чем человек должен быть воспитан. Вдохновленный Сайидом Кутб, он говорит, что моджахед будет свободен потому, что джихад означает освобождение и самоосвобождение. Абу Катада заканчивает, поощряя каждого молодого мужчину, который читает этот обзор, противостоять своей эгоистичной душе и вредным привычкам и выбрать единственную вещь, которая может спасти человеческое существо, а именно джихад. ${ }^{18}$

Одной из причин по которым Абу Катада расходует столь много энергии на Битву при Ухуде и говорит о ней с благодарностью, это то, что эта битва была большим испытанием, которое было нужно, чтобы выделить «группу победителей» из числа настоящих моджахедов. Однако, другой причиной является то, что в его интерпретации это та ситуация, в которой находятся мусульмане сегодня (книга была опубликована в 2012 году). Бог проверяет моджахедов великим испытанием. Они добились неожиданной

16 al-Filastini, al-Muqaraba li nazilat al-'asr, стр. 116.

17 Там же, стр. 145.

18 Там же, стр. 461. 
победы над Советским Союзом в Афганистане и они чудотворным образом добились успеха в нападении на самый большой город США. Но после этого американцы контратаковали, Усама Бен Ладен был уничтожен, и да, мусульмане дезертировали. Сейчас более, чем когда-либо есть потребность в высоком духе и презрении к смерти: моджахеды должны любить испытания, которым их подвергает Бог.

\section{Заключение}

ИГ и АК являются соперниками в Сирии, Йемене, Северной Африке и в многих других местах. Как показано в других статьях этого специального издания, у этих двух движений есть разные стратегии в отношение к местному мусульманскому населению, и разные взгляды на использование крайнего насилия. Другим большим отличием является то, что ИГ осуществляет контроль над вполне определенной территорией, которую это движение объявляет государством с определенными государственными функциями. Большое число видеозаписей, приходящих из ИГ, показывают не насилие, а школы, суды, полицию, рынки и законопослушных граждан. Есть и другое важное отличие: ИГ глубоко заинтересовано в приходе Халифа и в присяге людей на верность ему. Если они не хотят присягать, то они являются вероотступниками и должны быть казнены. Как мы видели, это одно из основных отличий от таких идеологов как аль-Макдиси и Абу Катада.

В этой главе рассматривается представление движения о халифате и политической власти и концепция истории, куда уходит корнями это представление. И опять, контраст с АК очевиден. В идеологии АК, халифат это предмет будущего, который мусульмане реализуют в один прекрасный день, но это не является главным фокусом движения. Правоверные все еще слишком слабы для этого. Наоборот, им нужно консолидироваться. Они как первые мусульмане, которые мигрировали из Мекки в результате исхода под предводительством Мухаммеда, и которые начали длительную войну против этого города. Они находятся на определенном этапе этой войны; в спаде, последовавшем за Битвой при Ухуде и поражения, которое отделило овец от козлов. Это было в 625 году.

ИГ, с другой стороны, в ментальном плане находится в 633 году. Пророк мертв, Абу Бакр является избранным и произносит свою инаугурационную речь, а восстание арабских племен почти подавлено. Битва, которая предстоит, это не Битва при Ухуде, а Битва при Убулла, и после нее следует присоединение Ирака и падение Персидской империи. Тогда как в идеологии АК мусульмане в борьбе выходят из состояния слабости и находятся в оборонительной позиции, идеологи ИГ считают, что их движение находится в другом положении: они остаются и находятся на грани расширения в великих мусульманских завоеваниях. Они уже чеканили свои собственные монеты, динары, и назначали губернаторов в отдаленные провинции. 
Это все еще время испытаний, а Пророк мертв. Но Бог создал группу победителей, и пришло время строить государство и расширяться.

\section{Об авторе}

Якоб Сковгаард-Петерсен является доцентом по арабским и исламским исследованиям в Университете Копенгагена. Его сфера это современные исламские средства массовой информации и исламское мышление, и современная роль мусульманских ученых, улемы. 